THE dangers of an explosion of gas, such as that which occurred on the evening of the $5^{\text {th }}$ inst, in Bedford Street, are not, it would seem, limited to the immediate vicinity of the accident.

At about $7 \mathrm{p.m}$. on that day I was reading in a room, which from its position at the back of the house being rather dark, required a light, when I was startled by a sudden rush of the flame from the single gas-burner upwards for about two feet-it immediately subsided, again blazed up, and repeating this a third time sank, and went out altogether.

I thought something had gone wrong in the pipe, and that the passage of the gas was interrupted, but on applying a match it ignited and burned naturally, though with a feebler flame than before.

It was fortunate that I was in the room to turn off the escaping gas, or some serious mischief might have occurred when next any one had entered the room to find gas and air mingled into an explosive compound. I found that two other gas lights in passages had been extinguished at the same time, attention having been called to them by the smell of escaping gas.

As the distance of my residence-Granville Place, Portman Square-is more than a mile from the site of the explosion, it is interesting to note the distance to which the impulse extended.

As no further disturbance occurred, and as the phenomena noted happened synchronously or nearly so with the explosion, and as the gas-pipes here are, I believe, branches of the same source of supply, I assume that what I observed and have described was in some way caused by the explosion.

Fortunately it was at an hour when the gas was not generally burning, or other accidents might have resulted. It would be interesting to know if others observed similar effects of the explosion.

July ro

J. FAYRER

\section{The Tay Bridge}

THERE are two interesting scientific questions, apart from engineering proper, which are suggested by the late inquiry, although no reference seems to have been made to them in the reports.

The first is the origin of the extraordinary flash seen at the moment of the downfall of the bridge by many spectators several miles away. It is scarcely doubtful that an impact was the only possible cause.

The second is the important question of the amount of windpressure which would suffice to force a train bodily off from the top of the bridge at a place where it was not within the girder. No strength of columns could then prevent an accident.

The flash seems to prove that the train had been blown off the rails, and had come into violent contact with the sides of the bigh girders. Then, and not sooner, the piers were subjected to a strain they were unable to bear.

G. H.

\section{"Geology of the Henry Mountains"}

I LATELY received, through the Home Office at Washington, a "Report on the Geology of the Henry Mountains," by G. K. Gilbert, being a portion of the "Geography and Geology of the Rocky Mountains." With the merits or demerits of this paper I am not concerned. I am not prepared, however, to pass in silence and without protest the following paragraphs, which I find at p. 76 :- "Bischof attempted, by melting eruptive rocks in clay crucibles, to obtain their ratios of expansion and contraction, but his method involved so many sources of error that his results have been generally distrusted. He concluded that the contraction, in passing from the molten to the crystalline state, is greater in acidic than in basic rocks. Delesse, by an extended series of experiments in which crystalline rocks were melted and afterwards cooled to glasses, showed that acidic rocks increase in volume from 9 to 1 I per cent, in passing from the crystalline state to the vitreous, while basic increase only 6 to 9 per cent. Mallet concluded, from some experiments of his own, that the contraction of rocks in cooling from the molten condition is never more than 6 per cent., and that it is greater with basic than with acidic rocks; but considering that the substances which he treated were artificial and not natural products, that his methods were not uniform, and that he ignored the distinction between the vitreous and the crystalline, of which Delesse had demonstrated the importance, no weight can be given to his results."
It would be difficult to compress into the same number of lines a greater amount of erroneous statement than is to be found in the above quotation. Bischof's results were never distrusted by geologists, by whom they were repeatedly quoted, until in my paper on the " Nature and Origin of Volcanic Energy," read to the Royal Society, June, 1872, and printed in Phil. Trans., I pointed out the errors incidental to Bischof's method of experiment, and at the same time directed attention to the strange arithmetical blunder of Bischof himself, by which his deductions from his own experiments are rendered still wider from the truth.

The experiments of Delesse, which I presume are referred to, were made on so small a scale that no deduction as to the total contraction between the liquid and solid state of any rock can be inferred from them. Coming now to Mr. Gilbert's summary condemnation of my own experiments on the total contraction of basic slags from the iron-smelting furnaces of Barrow (Cumberland), an account of which is given in my paper already referred to, and printed in the Phil. Trans. for 1873, some of the chief results of which are to be found in p. 20r, I have to remark that no other experiments on the subject, conducted on the same great scale, and with equal precautions to insure exactness, have ever been made and published. No experiments have ever been made upon the contraction of lava as flowing from a volcano and its solidification on cooling, but I have given comparative analyses of natural lavas, and shown their almost identical composition with that of the slags employed by me. It is incorrect to state that I have ignored the difference between the vitreous and crystalline condition; all the melted matter experimented on by me having, from the large bulk of melted matter, cooled in the crystalline state. Whether then any justification can be adduced for Mr. Gilbert's sweeping and unsupported statement that "no weight can be given" to the results of my experiments I leave to the judgment of men of science who have impartially read my results.

London, July 7

\section{Intellect in Brutes}

The Central Prison at Agra is the roosting-place of great numbers of the common blue pigeon; they fly out to the neigh. bouring country for food every morning, and return in the evening, when they drink at a tank just outside the prison walls. In this tank are a large number of freshwater turtles, which lie in wait for the pigeons, just under the surface of the water and at the edge of it. Any bird alighting to drink near one of these turtles has a good chance of having its head bitten off and eaten ; and the headless bodies of pigeons have been picked up near the water, showing the fate which has sometimes befallen the birds. The pigeons, however, are aware of the danger, and have hit on the following plan to escape it. A pigeon comes in from its long flight, and, as it nears the tank, instead of flying down at once to the water's edge, will cross the tank at about twenty feet.above its surface, and then fly back to the side from which it came, apparently selecting for alighting a safe spot which it had remarked as it flew over the bank; but even when such a spot has been selected the bird will not alight at the edge of the water, but on the bank about a yard from the water, and will then run down quickly to the water, take two or three hurried gulps of it, and then fly off to repeat the same process at another part of the tank till its thirst is satisfied. I had often watched the birds doing this, and could not account for their strange mode of drinking till told by my friend, the superintendent of the prison, of the turtles which lay in ambush for the pigeons.

The same friend had a couple of Hill Mynahs (Gracula religiosa) the most wonderful bird for mimicry which I have come across, not excepting the grey parrot of the West African coast. One of these birds, when hung out in the verandah during the afternoons, used to amuse itself by calling the fowls together, imitating the call of their keeper so well that they us $d$ to flock together under the cage, when the bird would bu st out into a very good imitation of a human laugh, as if it quite enj yed the fun of taking in the fowls. Have birds the sense of amusement? This one certainly seemed to derive gratification from the way in which it had cheated the fowls.

Roorkee, June 21

W. W. NICHOLLS

\section{The Volcanic Dust from Dominica}

SOME months ago, through the kindness of Messrs. Alexander Agassiz and S. H. Garman, some of the volcanic ashes which fell in Dominica on January 4 were placed at my disposal. On 